\title{
Los programas informativos en la Segunda Cadena: proyectos y realidades (1966-1975)
}

\author{
Juan MARTÍN QUEVEDO \\ Universidad Internacional de La Rioja / Centro Universitario Villanueva \\ juan.martin@unir.net
}

Recibido: 04/02/2014

Aceptado: 10/03/2014

\section{Resumen}

La Segunda Cadena de TVE fue fundamental en el intento de abordar dos de las demandas de la audiencia televisiva de los 60 en política informativa: una información más libre y menos censurada, y un aumento de la información local. Este estudio describe y analiza los cambios en la política informativa de La 2 a través de la reconstrucción de la totalidad de la programación informativa emitida en aquellos años, así como de fuentes secundarias, como prensa, obra memorialística y documentación oficial de TVE. Los resultados mostrarán el tímido y corto esfuerzo por regionalizar la información, truncado a la altura de 1968, y las dificultades que se experimentaron para poner en marcha un informativo independiente para la Segunda Cadena, que se dilató hasta mediados de los setenta.

Palabras clave: TVE, UHF, programación, franquismo, información.

\section{News Programmes in TVE-2: Projects and Realities}

\begin{abstract}
TVE's Second Channel was key to tackle two of the most pressing demands of sixties' television audience about news policies: a freer and less censored journalism, and more local information. This study describes and analyzes the changes that La 2 news policies suffered through the reconstruction of the whole programming of those years, as well as secondary sources, as press, memoirs and official documents of TVE. The result will depict the shy and short-lived effort to provide regional information, cut short as soon as 1968, and the difficulties to put on the air an independent news programme for the Second Channel, which had to be delayed until mid seventies.
\end{abstract}

Keywords: TVE, UHF, programming, francoism, news.

Referencia normalizada: MARTÍN QUEVEDO, Juan (2014): "Los programas informativos en la Segunda Cadena: proyectos y realidades (1966-1975)". Estudios sobre el Mensaje Periodístico, vol. 20, Núm. especial, pp. 73-89. Madrid, Servicio de Publicaciones de la Universidad Complutense.

Sumario: 1. Introducción. 2. Una cadena poco estudiada. Objetivos y metodología. 3. La información en la Segunda Cadena: características generales. 4. En busca de una voz propia. Los telediarios. 5. Programas informativos para minorías. Los otros programas de actualidad. 6. Un tímido intento de descentralización. La información regional. 7. Conclusiones. 8. Referencias.

\section{Introducción}

Los años 60 suponen un punto de inflexión fundamental tanto para el régimen franquista como para la televisión española. El desarrollismo posibilitado por la apertura económica de finales de los cincuenta, la ayuda internacional, el turismo y las divisas enviadas por la emigración cristalizaron en la tímida aparición de una clase media que, con dificultades, comenzó a conformar una sociedad de consumo que demandaba otras formas de ocio y de expresión a lo largo de la década de los 60.

El nacimiento de esta sociedad de consumo está ligada a la televisión, un medio moderno y capaz de convertirse en "un escaparate en cada hogar" para los anunciantes, como rezaba el eslogan de la época. Televisión Española (a partir de ahora, TVE) 
fue un testigo de excepción de ese proceso a través de su transformación de un medio que emitía pocas horas al día y con un limitado alcance (sólo se recibía en Madrid y Barcelona), a una televisión moderna precisamente en los años 60 . El cambio fue paulatino, y tuvo varias dimensiones: el aumento de las horas de emisión, la creación de teleclubes y la mejora de la profesionalidad en la realización de los programas.

Esta modernización económica y social propició el surgimiento de unas demandas culturales e informativas - pero cuya vertiente política a nadie se le escapaba- desde diferentes ámbitos de la sociedad. Por un lado, la naciente clase media de las grandes urbes demandaba una información más fiel y menos censurada. Por otro, desde las regiones extracapitalinas, particularmente aquellas desde aquellas en que el nacionalismo había tenido un mayor peso histórico, había un deseo creciente de acceder a una programación más cercana a lo local, tanto en la cultura y la lengua como en las noticias. Hubo que dar respuesta a estas nuevas exigencias dentro de los estrechos límites del marco ideológico y político de la dictadura.

La Segunda Cadena de TVE fue clave en la atención de ambas demandas, porque reunía dos características que la hacían especialmente apropiada: por una parte, solamente se recibía en algunas capitales de provincia y sus zonas aledañas, incluidas la mayor parte de Galicia, País Vasco y Cataluña. A la altura de 1974 Juan José Rosón, director general de Radio y Televisión admitía que "[el segundo canal] sólo se recibe aceptablemente en un 30\% del territorio nacional" (Tele Radio,1974b: 33). Su audiencia, por lo tanto, era predominantemente urbana y de clase media. Por otro lado, era un canal cultural y minoritario, a menudo utilizado como laboratorio de experimentación de programas. Por lo tanto, era viable probar la descentralización primero, y la liberalización informativa después, en la confianza de que el impacto en la sociedad española sería controlado.

\section{Una cadena poco estudiada. Objetivos y metodología}

El período franquista de la Segunda Cadena apenas ha sido objeto de atención por parte de los investigadores, especialmente en los últimos años. La mayor parte de las referencias se encuentran en monografías sobre la historia de Televisión Española en general, sean académicas (Bustamante, 2008, Palacio, 2008 y Rueda y Chicharro, 2006) o periodísticas (Díaz, 2006), pero en ningún caso se ha abordado el segundo canal desde el punto de vista de la programación y su contenido. La mayor parte de las investigaciones se han centrado en aspectos muy específicos, como la ciencia (Albertos y Ortega, 2009), el deporte (Bonaut, 2009), las series (Diego, 2010), o la historia (Hernández, 2008), con algún capítulo dedicado a la televisión en obras colectivas de temática más amplia (Ibáñez, 2008 y Palacio, 2012).

Sí ha habido algunos esfuerzos para abordar la programación general de las cadenas públicas en aquellas décadas, bien a través de una muestra (Gómez-Escalonilla, 2003) o reconstruyendo la programación de algunos años en su totalidad (Carreras, 2009), pero se han centrado en la Primera Cadena: la Segunda ha sido obviada o se ha extraído una muestra tan pequeña que hacía imposible el estudio pormenorizado.

Tampoco existe ningún análisis académico específicamente sobre los programas informativos en el UHF (Ultra High Frequency). Este estudio pretende por lo tanto llenar esa laguna y describir los cambios en la política informativa de La 2 a través del 
análisis de la totalidad de la programación informativa emitida durante el franquismo, así como de fuentes secundarias, como prensa, obra memorialística y documentación oficial de TVE.

La hipótesis de partida es que los programas informativos supusieron un factor fundamental de modernización de la información televisiva en España, pero que estos esfuerzos modernizadores quedaron parcialmente truncados a principios de los setenta. Por un lado, la iniciativa sufrió reveses importantes: el tímido y efímero esfuerzo por regionalizar la información, que se frustró por falta de medios a la altura de 1968 y la paulatina desaparición de contenidos minoritarios en los programas de actualidad y deportes, probablemente por desinterés de la audiencia. Pero también logró éxitos relevantes, a pesar de las dificultades tanto políticas como económicas: la puesta en marcha de un informativo propio para la Segunda Cadena y el fin de la dependencia de la TVE-1.

La primera tarea para el análisis de los programas de la Segunda Cadena ha consistido en la elaboración una base de datos con la totalidad de lo programado entre el 15 de noviembre de 1966, día en que se inauguraron oficialmente las emisiones independientes del Segundo Programa, y el 20 de noviembre de 1975, fecha de la muerte de Franco.

Uno de los problemas que se han planteado son las divergencias entre lo programado y lo realmente emitido. Ha sido difícil establecer una distinción, pero se ha recurrido a fuentes diversas para contrastar los datos. La primera ha sido la revista oficial de TVE, Tele Radio, que incluía la programación semanal. A través de ella puede hallarse lo que Televisión Española esperaba emitir. Las fuentes de contraste han sido los diarios $A B C$ y La Vanguardia. TVE remitía diariamente una nota con los programas que se debían emitir al día siguiente para su publicación en la prensa general, por lo que los cambios de programación que se operaban después de publicada Tele Radio aparecen aquí reflejados.

No obstante, la programación no aparece reflejada de forma exhaustiva en los periódicos: habitualmente sólo se señalan los programas más destacados (que, en ocasiones, no son los mismos en $A B C$ que en La Vanguardia). Cuando ha sido posible reconstruir la programación mediante el contraste con otros medios y con otros días sin existir incompatibilidad entre fuentes, se ha hecho. Cuando no ha sido posible establecer una sola versión por la divergencia de datos, se han consignado las dos.

En la base de datos se han especificado los siguientes campos de cada emisión (unidad de análisis): un primer bloque para situar cronológicamente el programa (día de la semana, fecha, hora de inicio, hora de finalización), y un segundo con aspectos cuantitativos y cualitativos del mismo: duración en minutos (incluida publicidad), el nombre del programa, título de la emisión específica (nombre del episodio o película, invitados al programa, etc.), otra información sobre el mismo (sinopsis, equipo técnico,...), el género (entretenimiento, información o divulgación) y el tipo de programa (en el caso de la información: actualidad, telediario, deporte, regional, especial y cultura).

Además de reconstruir las parrillas de aquellos años, también se ha llevado a cabo una labor de recuperación de los contenidos de los propios programas, así como de la recepción de crítica y público, cuando ha sido posible. Desde 1972, con Adolfo Suárez como director general de TVE, se elaboraba el Panel de Aceptación de programas 
que medía con una puntuación de 1 a 10 el grado de aprobación de algunos programas por parte de quienes eran sus espectadores, pero no daba cuenta de la cantidad de espectadores. Lo confeccionaba semanalmente el Servicio de Estudios de Contenidos y la prensa reflejaba sus resultados de cuando en cuando. También en 1969 se encargo una encuesta sobre la audiencia de TVE, pero esta iniciativa no tuvo continuidad. Por tanto, ha sido necesario recurrir a la prensa de la época y a las memorias de protagonistas, no demasiado abundantes, pero fuente útil para conocer los entresijos de la elaboración estas producciones.

\section{La información en la Segunda Cadena: características generales}

El modelo europeo de televisión pública a mediados de los años 60 se apoyaba en los tres géneros fundamentales televisivos: la divulgación, el entretenimiento y la información. La proporción exacta en que se equilibran los tres géneros era una de las señas de identidad de cada canal. No obstante, desde principios de los 60 , se tendía a imitar en lugar de buscar fórmulas propias adaptadas a las características de cada público:

"Se ha de notar que los receptores belgas, canadienses, franceses, húngaros y japoneses son finalmente parecidos, como si existiera una demanda de programas que respondiera al modelo de: información un $22 \%$, cultura y educación un $6 \%$, y entretenimiento un $72 \%$; como si, sean cuales sean los programas difundidos, la audiencia restableciera en su consumo un equilibrio universal, que resistiera a la programación paternalista o demagógica, e impusiera un modelo de consumo que fuese (al menos en los países industrializados) bastante uniforme" (Thoveron, 1982: 91 y ss.).

No obstante, la Segunda Cadena, en la línea de los segundos canales culturales que estaban proliferando en el resto de Europa, presentaba un balance de contenidos con un peso mucho mayor en la programación cultural. Aunque el entretenimiento $(60 \%)$ siguió siendo el género hegemónico y la información (19\%) se mantenía en un porcentaje muy similar a otras cadenas, fue la divulgación (21\%) la que aumentó significativamente su peso respecto al modelo generalista. Además, todos los programas, independientemente de su género, estaban impregnados de un espíritu culturizante muy marcado que configuraba la identidad de la cadena:

"La oferta programática de La 2 resulta muy llamativa a nuestros ojos contemporáneos; no ha habido en la historia de las programaciones en España un modelo tan cercano al concepto de televisión cultural; la parrilla está escorada hacia el cine de autor (ciclos en versión original tales como Satyajit Ray, Kenzi Mizoguchi o el cine de los países del Este, imposibles en la actualidad en la televisión generalista sea cual sea su hora de emisión) y hacia la producción propia de obras dramáticas (Teatro de siempre, Hora 11, Estudio en negro,...)" (Contreras y Palacio, 2008: 59).

Además, el tiempo que se dedicaba a cada uno de los géneros se traducía en prácticas programativas muy diferentes. Con un $21 \%$ del tiempo de emisión total (2.980.6 horas), el apartado de información no quedaba muy lejos de esa proporción estándar de la televisión mundial de $22 \%$ de información, $6 \%$ de cultura y $72 \%$ de entretenimiento. En otras palabras, la información tenía un peso muy similar en la programación de la televisión pública del franquismo respecto a las televisiones de países 
más modernizados, independientemente de si se basaban en modelos de televisión pública o comercial.

La presencia destacada de la información en la programación de la Segunda Cadena se refiere a las horas emitidas, y no refleja ni la importancia que el Régimen concedía a los informativos, mucho más vigilados que cualquier otro tipo de programa, ni permite establecer ningún tipo de paralelismo con el periodismo -más libre y plural- que existía en otros países.

Los programas dedicados a la información pueden clasificarse en tres grandes grupos (ver gráfico 1): los telediarios, el programa más emitido y eje fundamental de la programación; los programas que abordaban noticias relevantes pero no de actualidad inmediata: deporte, cultura y actualidad; y los programas de información regional, que protagonizaron un breve intento de descentralización.

\section{Gráfico 1. Porcentaje de tiempo emitido de información según tipo de programa (1966- 1975)}

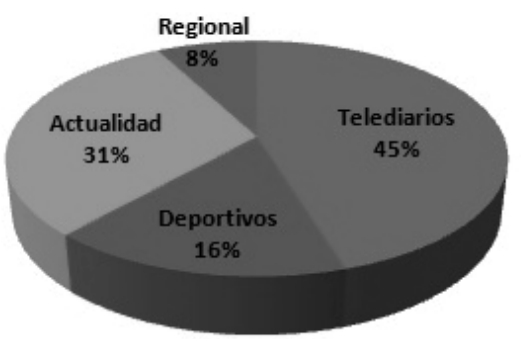

Fuente: elaboración propia.
Esta distinción se hace patente no sólo en la temática, sino también en cómo fueron programadas cada una de estas categorías: los telediarios se emitieron casi exclusivamente en el prime time, mientras que el resto de los programas ocuparon otros espacios de la parrilla. Los programas regionales se situaron mayoritariamente durante la franja vespertina, al entenderse que eran programas diferentes a

los telediarios, más centrados en la actualidad local y sobre todo en las fiestas populares. Algo similar ocurrió con los programas de actualidad, que se repartieron casi en la misma proporción entre la tarde y el prime time (ver gráfico 2).

\section{Gráfico 2. Distribución de los programas informativos según franja de emisión (1966-1975)}



n Sobremesa (14:30-17:00)

- Tarde (17-21:30)

n Prime time (21:30-23:30)

- Madrugada (23:30 en adelante) 
En definitiva, la información en el UHF tuvo dos funciones programativas claramente diferenciadas: la primera se refiere al papel del telediario como organizador de la programación. El telediario servía para dividir la programación vespertina, que se dirigía a aquellos espectadores que estaban en casa y viendo la televisión a las ocho de la noche, de una programación concebida para ser vista -al menos potencialmentesólo por los adultos. Si a esto se le suma que durante mucho tiempo solamente hubo en televisión el telediario de la Primera Cadena -y más tarde el de la Segunda para quienes lo recibieran, pero la variedad de elección seguía siendo limitada-, la importancia social del mismo, incluso en una sociedad con un mayor consumo de radio que la actual, es fácilmente comprensible.

La segunda, como se ha señalado, era la de los programas de información menos pegados a la inmediatez de la noticia. Estos servían para rellenar huecos en la programación de tarde, porque se entendían como oferta diferente e independiente del telediario.

\section{En busca de una voz propia. Los telediarios}

Los programas más emitidos fueron los telediarios, esto es, los programas que, bajo uno u otro nombre ${ }^{1}$, ofrecían un sumario general de la actualidad y que se emitían diariamente a la misma hora, a veces con una edición diferenciada para los días laborables y otra para el fin de semana.

El $45 \%$ de los programas informativos correspondieron a los telediarios, un total de 1.326,3 horas. Debido a las escasas horas que emitía la Segunda Cadena -5 horas de televisión vespertina-, sólo había una edición de los telediarios, la nocturna. La cantidad no resulta demasiado elevada si se tiene en cuenta que se trata de un programa que se emite diariamente. La razón es que su duración, que varió a lo largo del tiempo, fue siempre reducida.

En los primeros meses, desde noviembre de 1966 hasta mayo de 1967, Telediario estaba en antena diariamente 15 minutos. Después se amplió a 20 minutos: (hasta mayo de 1968), con una breve etapa en que duró 25 minutos (octubre-diciembre de 1967). Seguidamente pasó a 30 minutos (mayo de 1969), entrando en una dinámica de duración irregular: desde los 20-25 minutos a los 35 minutos, para estabilizarse a mediados de 1973 y hasta el final de la etapa analizada en la media hora. Los fines de semana, por otra parte, los informativos tenían una duración menor, alrededor de los 15 minutos. No obstante, hubo algunos programas especiales con una emisión superior a la media, como el lanzamiento del Apolo XIV desde $\mathrm{Cabo} \mathrm{Kennedy}^{2}$, al que se dedicaron 55 minutos.

1 El más frecuente fue simplemente Telediario (1.082,55 horas), pero también aparece consignado Noticias en el Segundo Programa (148,67 horas) o Noticias 2 (64,73 horas). Por desgracia, es imposible saber si el cambio de denominación responde a una laxitud a la hora de reflejar la programación, a un cambio de nombre real de un mismo programa, a un nuevo programa informativo o a un cambio de nombre que responde a un cambio en su estructura $u$ orientación, dentro de las limitaciones del sistema franquista.

2 Emitido el 31/01/1971. 
Estos cambios en el tiempo de emisión de los telediarios son consecuencia de su propio proceso de constitución: la Segunda Cadena pasó de conectar con los telediarios de la Primera en los primeros años a desarrollar su propia plantilla de periodistas con el fin de ofrecer con un programa independiente, aunque este empeño tuvo sus matices:

"Surge una novedad digna de ser destacada: por primera vez, la Segunda Cadena va a emitir información propia. Noticias 2 es el título del espacio. Aún cuando este programa tiene carácter propio y una cierta independencia informativa, recoge aquellas noticias más destacadas de las ya emitidas en la Primera Cadena" (Tele Radio, 1970: 10-13).

El intento de La 2 por ofrecer una información totalmente independiente de la Primera se encontró con muchas dificultades. El responsable de sacar adelante ese proyecto fue Francisco Ruiz Elvira, nombrado en 1974 jefe de los servicios informativos de la Segunda Cadena. Era un hombre con amplia experiencia: había desempeñado importantes cargos en la agencia EFE -jefe de servicios especiales, más tarde de información nacional, posteriormente corresponsal en Italia y Estados Unidos, y, finalmente, redactor jefe de exteriores- y en Radio Nacional de España -jefe de servicios informativos -3 .

Ruiz de Elvira proyectó inaugurar los servicios informativos de La 2 en abril de ese mismo año, pero el montaje de los estudios, la organización de las redacciones y la adecuación de un equipo técnico exigió más tiempo del previsto (Tele Radio, 1974b: 9).

Finalmente, en noviembre comenzaron las emisiones del telediario propio del UHF. Los motivos del retraso se achacaron a "dificultades técnicas", que sólo se habían superado "en parte" (Tele Radio, 1974f: 69). Ello motivó persistentes rumores sobre su inminente desaparición prácticamente desde su aparición:

"Los espacios informativos de la Segunda Cadena no sufren -por ahora- ningún cambio aunque los rumores surgidos hace unas semanas de que desaparecerían para volver a utilizar los de la Primera Cadena no se han disipado todavía. Pero, TVE, por el momento mantiene firme que el UHF seguirá con su llamémosle "independencia" informativa" (Marimón, 1974b: 43).

La espera, no obstante, no fue baldía: junto al telediario propio La 2 incorporó a su programación otro programa informativo de 90 minutos, Temas 74, continuado al año siguiente en Temas 75, aunque con una duración reducida a los 60 minutos. Realizado también por los servicios informativos, el programa se emitía cada viernes y en

3 Otros cargos menos vinculados a los informativos provenían de la promoción interna. Por ejemplo, en septiembre de ese mismo año Marino Peña, que había sido una persona fundamental en la Segunda Cadena, se convirtió en director adjunto de TVE. Peña era en aquel momento director adjunto de Programas, y antes había desempeñado otros cargos vinculados a la programación, como secretario técnico de programas de la Segunda Cadena y jefe de los Servicios de Programación de TVE, además de director del segundo canal cuando Salvador Pons promocionó a director de TVE (Tele Radio, 1974c) Peña era cuñado de Rodolfo Martín Villa y había llegado a la Segunda Cadena junto al propio Pons en verano de 1966 (Tele Radio, 1986: 47). 
domingos alternos, con un contenido centrado en el análisis de la actualidad general, no en la información noticiosa.

Cumplida su misión, Francisco Ruiz de Elvira volvió a Radio Nacional, primero como jefe de informativos (Tele Radio, 1974g: 42) y, tras la muerte de Franco, como director del ente (Tele Radio, 1976a: 15). A pesar de ello no abandonó su cargo en Televisión Española hasta 1976, cuando fue sustituido por Mauro Muñiz (Tele Radio, 1976b: 10).

\section{Programas informativos para minorías. Los otros programas de actualidad}

La segunda categoría en cuanto a horas de emisión fue la actualidad, con 895,4 horas, un $30,5 \%$ del total. Se trata de programas que o bien ofrecían información sobre temáticas específicas -el cine, el motor, sociedad-, o bien reportajes sobre temas que eran noticia, pero que no exigían una difusión inmediata. El más destacado de estos programas fue Cuestión urgente (1967-1970), un programa de reportajes sobre problemas sociales que se emitió durante 82,95 horas.

La característica más remarcable de Cuestión urgente y lo que lo convirtió en un programa único en la parrilla tanto de la Primera como de la Segunda Cadena fueron los temas que se abordaron y la manera abierta, también piadosa, con la que se trataron. El director del programa era un sacerdote, Joaquín Martínez Roura. También escribía los guiones: hasta el 19/12/1967 compartió la responsabilidad de la emisión con Luis Espinel durante la primera etapa, para seguir en solitario durante una etapa (entre el 02/01/1968 y el 05/06/1968) y, finalmente, con José Verde Aldea hasta el final del programa. La realización recayó sobre Esteban Durán hasta el 08/10/1969, y a partir de entonces se fueron alternando en el puesto de realizador Manuel Rato, Gerardo N. Miró y Antonio Jaume.

Así explicaba Martínez Roura la orientación de su programa:

"Cuestión urgente nació como programa religioso, porque en todos los temas tratados intentamos dar una respuesta cristiana al problema [...] pero podemos decir que es también un programa cultural-informativo. [...] Pretende presentar un problema narrado por los que lo sufren -las víctimas- y completado por la aportación de unos especialistas en el mismo. [...] Si esto no es posible, aunque el problema exista, lo desechamos como tema adecuado" (Tele Radio, 1970: 29).

Algunos de los temas tratados tenían una vertiente fundamentalmente informativa, como los dos programas dedicados a la enseñanza en España ${ }^{4}$, a la mecanización y la automatización industrial ${ }^{5}$, a la contaminación atmosférica ${ }^{6} \mathrm{o}$ el que trató sobre los ladrones de coches ${ }^{7}$. No obstante, el grueso de los problemas analizados tuvo una indudable impronta social, tanto en la temática como en su tratamiento, muy alejado de lo estrictamente informativo. Por ejemplo, el primer programa se dedicó al alcoholismo:

4 Emitidos el 02/01/1968 y el 09/01/1968.

5 Emitidos el 05/04/1969 y el 12/03/1969.

6 Emitido el 07/05/1969.

7 Emitido el 06/02/1970. 
"El vino que alegra el corazón del hombre, y tiene un intenso sentido de comunicación, se puede convertir, al abusar de él, en un factor de degradación. En ciertas naciones el abuso del alcohol constituye una plaga social. ¿Existe también en nuestra sociedad el problema del alcoholismo? ¿Qué proporciones alcanza? ¿Cuál es el misterio del alcohólico? ¿Hay esperanza para él?” (Tele Radio, 1967d)

De la misma manera, la sinopsis del programa titulado "Gastronomía y hambre en el mundo"s era toda una declaración de intenciones:

"No; no es posible cerrar los ojos a lo que el P. Lebret ha llamado "el drama del siglo". Una humanidad dividida desgarrada en su carne y en su alma. El 62 por 100 de la población mundial no puede satisfacer el hambre. El dilema con que se enfrente el mundo en la actualidad es este: el crecimiento demográfico tiende a hacer a los pobres cada vez más pobres. El duro contraste entre estas dramáticas realidades y la conducta de los hombres queda denunciado en este programa de Cuestión urgente. (Tele Radio, 1969).

Cuestión urgente se atrevió a plantear también programas sobre algunos asuntos que podían resultar controvertidos para la sensibilidad católica, como por ejemplo el celibato sacerdotal ${ }^{9}$, las madres solteras ${ }^{10}$, las monjas $^{11} \mathrm{o}$ los curas obreros ${ }^{12}$.

El programa estuvo acompañado, en casi todas sus emisiones, por la controversia, con defensores entregados y acérrimos detractores.

8 Emitido el 29/01/1969.

9 Emitido el 14/11/1967. Lejos de la autocomplacencia, Cuestión urgente abordó el debate de forma abierta: "La sinceridad imperante de nuestro tiempo va desvelando temas que antes se consideraban tabú. También le ha llegado el turno al celibato de los sacerdotes. ¿Por qué no se casan los sacerdotes? ¿El celibato no resulta anticuado? ¿Qué opinan los jóvenes sacerdotes de la virginidad?".

${ }^{10}$ Emitido el 21/08/1968. El resumen que apareció en Tele-Radio mostraba una postura alejada de la censura de las madres solteras, e incluso comprensiva: "Queramos o no, el problema existe. El caso de las madres solteras era visto hasta hace poco con una total intransigencia por parte de unos y como un caso de ignominia por parte de otros. En este programa les ofrecemos testimonios personales y juicios sobre el problema de personalidades competentes en la materia. ¿Por qué se cierran todas las puertas de una rehabilitación social a quien más lo necesita?".

${ }^{11}$ Emitidos el 28/11/1967, el 05/12/1967 y el 10/07/1968. Una vez más, Cuestión urgente no intenta ocultar su voluntad de abrir un debate: "Pese a la diversidad incontable de hábitos, todos sabemos identificarlas: son monjas. Este nombre sugiere, hoy en día, una problemática especial. En un mundo donde el valor se mide por la utilidad, la vida de estas mujeres ha de estar sujeta a críticas y a revisión. ¿Qué hacen? ¿Qué sentido tiene su vida? Su vida, ¿es una evasión? Especialmente las religiosas de clausura, ¿son una realidad justificable en el mundo de hoy? "Cuestión urgente" quiere responder a estas preguntas a través del testimonio personal de las que viven consagradas a este ideal religioso y ha introducido sus cámaras en la clausura de algunos conventos para descubrir la actividad y el sentido de $\mathrm{s} u$ quehacer cotidiano".

${ }_{12}$ Emitido el 20/04/1968. 
"He recibido cartas impresionantes, confesando el impacto que les había producido un título determinado [...] al lado de las más numerosas protestas y escándalos, que también recibimos" (Tele Radio, 1970: 29).

Otro de los puntales importantes de los programas de actualidad fue $A$ todo gas (1966-1969), que se emitió desde el mismo inicio de la programación independiente de la Segunda Cadena durante media hora diaria (un total de 68,9 horas). Pese a lo que podría suponerse por su título, no se trataba de un programa deportivo, o al menos no principalmente deportivo:

"El parque automovilístico de nuestro país se encuentra en pleno desarrollo, pero gran número de conductores son nóveles: de aquí la necesidad de un programa de televisión capaz de orientar, estimular y fomentar el interés general por el mundo del motor. [...] Se plantean temas de orden técnico, deportivo, anecdótico, etcétera, de cara al usuario, al simple espectador, al especialista" (Tele Radio, 1967a: 26-27).

La estructura del programa se articulaba en torno a una primera parte compuesta por entrevistas, reportajes y filmaciones de actualidad, y una segunda, que no aparecía siempre, consistente en uno o más documentales cortos sobre la historia de los vehículos de motor en cualquiera de sus vertientes. A pesar de su estructura flexible, se mantuvo siempre pegado a cuestiones de relativa actualidad.

También el cine tuvo sus espacios dentro de la actualidad. Fueron dos: Revista de cine (1975-) y Pantalla grande (1966-1969). Del primero apenas hay registros, porque comenzó unos meses antes del final del período estudiado. Pese a ello, Revista de cine se emitió durante un total de 60,1 horas, una cifra destacable debida a su duración (90 minutos).

El contenido del programa variaba. Solía incluir una parte dedicada a noticias de actualidad, los directores y los actores más famosos del momento, y a veces una entrevista a un personaje de primera línea, como la dedicada a Mel Brooks ${ }^{13}$. Esta parte se completaba con un reportaje, como el monográfico dedicado a los premios de la Sociedad Cinematográfica de Londres ${ }^{14}$, o con un cortometraje propio o tráiler del último éxito de Hollywood. En la segunda parte se incluía un coloquio y un reportaje sobre algún aspecto de la historia del cine, o la serie de reportajes titulada "La vida cinematográfica en provincias" ${ }^{15}$.

Pantalla grande se definía como "revista semanal del cine". El guión, de Munsó Cabús, estaba estructurado en una primera parte de actualidad, con una entrevista a una figura destacada del cine español o internacional, un reportaje (a menudo sobre la filmación de una película), y una segunda formada por la sección Momentos estelares, en que se recordaban, a través de fragmentos filmados, películas o actores para el recuerdo, $\mathrm{y}$, finalmente, un fragmento de una película antigua. Todo ello en menos de 30 minutos.

\footnotetext{
${ }^{13}$ Emitido el 28/05/1975.

${ }^{14}$ Emitido el 26/03/1975.

${ }^{15}$ Que se emitió entre los días 02/07/1975 y el 24/09/1975.
} 
El segundo grupo de programas que formaron esta categoría fueron los deportivos, que ocuparon el $16,3 \%$ del tiempo dedicado a la información, unas 478 horas. Los programas dedicados al deporte ofrecían imágenes y comentarios sobre encuentros deportivos, pero no los retransmitían en su integridad. Su objetivo era informar sobre los resultados y analizar el deporte y los aspectos que lo rodeaban. En estos años se estrenaron tres programas. El más destacado fue El mundo del deporte (1966-1971). Comenzó con la Segunda Cadena, y en cinco años se emitieron 269,6 horas. El equipo planteaba así sus objetivos:

"El propósito de El mundo del deporte es el de llevar al espectador los deportes prácticamente desconocidos para el gran público. [...] Los deportes que escogemos preferentemente -explica Manuel Rato, realizador del programa, junto a Antonio Jaume- son aquellos minoritarios, para ampliar su difusión" (Tele Radio, 1967b: 12-15).

Destaca su estructura irregular. Por un lado, el programa se emitía cinco veces a la semana, pero cada una de las emisiones tenía una duración, un sumario y un equipo diferente, que respondía a ese planteamiento un tanto ecléctico del programa, que pretendía aunar la actualidad deportiva, la labor divulgativa de los deportes minoritarios y el simple y puro entretenimiento:

"Los martes, el espacio está dedicado a la actualidad, tiene veinte minutos de duración y se refiere a la jornada deportiva del domingo anterior. Los miércoles, El mundo del deporte se centra prácticamente en los deportes olímpicos y dura ocho minutos. Divulgación y curiosidades deportivas es el tema del espacio del viernes, también de ocho minutos. Estos tres "mundos" están realizados por Manuel Rato. De la realización de los espacios del jueves y sábado, ambos de trece minutos de duración, y que ofrecen entrevistas y divulgación e historia del deporte, respectivamente, se encarga Antonio Jaume" (Tele Radio, 1967b: 12-15).

El resto del equipo estaba formado por José Félix Pons y Vicente Martínez, los presentadores, y los guionistas Guillermo Sánchez y José María Zubeldía, que se fueron alternando, en ocasiones por separado, y otras veces juntos. A partir del 17/10/1967 se incorporaron al equipo a la realización Ricardo Soria, y al de guionistas Mari Carmen Hernández, que harían el programa de los martes. La dirección y redacción del programa de los miércoles recaería sobre Félix Martialay, con la colaboración de los redactores, Pedro González y Antonio Pascual de Riquelme.

El mundo del deporte fue sustituido por ;Más lejos! (1971-1973), un programa que durante sus 75 horas de emisión retomó en buena medida las secciones y el enfoque del anterior, si bien con una visión más informativa. Así se deduce de su presentación:

"La Segunda Cadena inicia este nuevo espacio dedicado al deporte en general. Junto a la información de actualidad, tendrán cabida el reportaje la retrospectiva, la historia de un récord, las plus marcas nacionales y mundiales, la promoción del deporte como actividad formativa y educativa" (Tele Radio, 1971).

El equipo técnico de ¡Más lejos! estuvo formado por profesionales que habían trabajado en la última etapa de El mundo del deporte: la realización corrió a cargo de José Luis Monforte, mientras que Juan Antonio Martínez Abajo se encargó de la coordina- 
ción, siendo José Félix Pons y Miguel Ángel Valdivieso sus locutores. La importancia que la Segunda Cadena atribuyó al programa queda clara en el hecho de dedicarle una hora semanal en un horario privilegiado, inmediatamente antes del telediario nocturno.

El tercer programa deportivo, heredero directo de ;Más lejos!, pero más centrado en esa faceta de información deportiva, fue Polideportivo (1973-), que empezó a emitirse inmediatamente después del fin de aquel, el 24/04/1973 y que continuó en antena más allá del período estudiado. Polideportivo mantuvo el mismo horario privilegiado de que había gozado iMás lejos!, durante 156,9 horas hasta noviembre de 1975.

Rodado en los estudios de Miramar, el programa mantuvo también en buena medida el equipo de ¡Más lejos! El guión, primero, y la dirección, más tarde, corrieron a cargo de Juan José González, mientras que la realización recayó sobre José Luis Monforte; fue presentado por Miguel Ángel Valdivieso, José Félix Pons y Juan José Castillo sucesivamente. Contó con una serie de colaboradores que variaba de programa a programa, pero entre los que cabe destacar a José Luis Marco, Miguel Ángel Valdivieso, Casanovas y Botines. A partir del primer trimestre de 1974 Polideportivo se emitía en directo, novedad que fue muy bien acogida por la prensa "ya que un espacio deportivo cobra muchos enteros al presentarse a cámara limpia" (Marimón, 1974a: 57).

El espacio gozó de las simpatías de la crítica especializada, que destacó no sólo sus cualidades técnicas, ya señaladas, sino también el hecho de que se tratara de un programa dedicado al deporte en general y no solo al fútbol "aunque la audiencia se mínima" (Marimón, 1974a: 57). Se diferenciaba así de espacios muy populares de la Primera Cadena como Estudio-Estadio. Ello no quiere decir que no se ocuparan de las novedades futbolísticas; antes al contrario, a partir de febrero de 1974 Polideportivo emitía reportajes filmados de todos los partidos de segunda división (Tele Radio,1974a: 61). A pesar de ser minoritario, Polideportivo vio su duración aumentada de la hora a los 90 minutos en octubre de 1974 (Tele Radio, 1974d: 47). Además, frecuentemente aparecían anunciados en prensa sus contenidos.

Una particularidad interesante es que Polideportivo incorporó como sección un programa que antes se había emitido independientemente durante 26,1 horas, Los combates del siglo (1971-72). El programa, con guión y dirección de Manuel Alcántara y realización de Enrique Fernández Porras, ofrecía dos combates históricos de un determinado mito del boxeo. Normalmente el primer combate representaba su momento de mayor gloria deportiva y el segundo aquel en que perdió el título o supuso, por algún otro motivo, una derrota remarcable.

\section{Un tímido intento de descentralización. La información regional}

Uno de los objetivos declarados de TVE en lo informativo pasaba por una cierta descentralización y una atención mayor a las distintas regiones de España, para lo cual la Segunda Cadena fue un instrumento privilegiado. A pesar de ello, tan sólo se dedicó a este propósito el 7,7\% del tiempo de información, unas 227 horas. El esfuerzo se limitó a dos programas que pretendieron dar respuesta a esta reivindicación recurrente del público que no vivía en Madrid.

El primero de ellos fue Crónica 2 (10.981 minutos), un espacio que pretendía dar cumplida información de la actualidad de las ciudades a las que llegaba el UHF (Tele 
Radio, 1967c: 87) durante las 183 horas que duró. Tuvo dos etapas claramente diferenciadas: una primera entre 1967-1969, y una segunda entre 1972-75. En la más temprana estuvo dirigido por Juan Blanco y Jorge Víctor Sueiro con un guionista que iba rotando según la región a que se dedicaba el programa: Guipúzcoa, Murcia, Vizcaya, Valencia, Zaragoza, Alicante, Galicia y Sevilla.

Se trataba de un programa de media hora diaria en el que cada emisión estaba dedicada a un centro regional, sin ninguna pauta discernible en la sucesión de los mismos. El formato, por otra parte, era de actualidad "blanda", esto es, más centrado en la actualidad local de largo recorrido que en las noticias más inmediatas. Su estilo se asemejaba más al reportaje de un estilo similar a Fiesta o Conozca usted España que al informativo tradicional. Así, los programas describían los cambios experimentados por las ciudades, su expansión y modernización, su gastronomía y atractivos turísticos.

La prensa acogió este esfuerzo descentralizador con una actitud decididamente entusiasta, aunque sin escatimar las críticas respecto a los problemas técnicos y artísticos del programa en sí:

"La Segunda Cadena ha iniciado con Crónica 2 el más serio intento informativo descentralizador. [...] Es una visión seria y sincera de las provincias, hecha por profesionales del periodismo radicados en ellas. [...] Es pronto para enjuiciar el intento que, como intento, es importante. Tanto, que necesita, todavía, de mejor pulso, de otra dinámica más concorde a la televisión. Gran parte de lo visto tiene más aire de reportaje cinematográfico que televisivo" (Tele Radio, 1967e: 109).

Tres años después, en la segunda etapa, Crónica 2 estuvo presentado y dirigido por Carlos Sentís, con Juan Manuel Mariño en la realización. El equipo se completaba con Eugenio Pena, Rosario Hernández y otros cinco periodistas. El mismo director explicaba así los objetivos del programa en esta etapa:

"Desde los comienzos de Crónica 2 se pensó que sería un poco ajeno al molde general, con posibles salidas a temas algo polémicos y conflictivos, ya que tienen mejor encaje en este programa. Este está pensado para un público menos mayoritario, e interesado específicamente en algunos temas más de formación que de información, y más de opinión que de simple relato o reseña" [...] [Crónica 2 persigue] proporcionar cierta trascendencia a los que, de otra manera, podrían pasar por la actualidad casi deslizándose, y, al mismo tiempo, inyectar cierto aire de comprensión. Por otro lado, quitar aburrimiento y solemnidad a temas que, con bastante frecuencia, se presentan envueltos en considerables dosis de engolamiento" (Tele Radio, 1975: 22).

A pesar de que la cita es un tanto ambigua en cuanto al contenido exacto del programa, la nula alusión a la información regional es bastante reveladora. Las referencias en prensa apuntan a un programa informativo ${ }^{16}$. El cambio completo de equipo, el paso de la frecuencia diaria a la semanal (a pesar de que se mantuvo la media hora

${ }^{16}$ Por ejemplo, la entrevista que se le hizo en el programa a Javier Ybarra, presidente de la Asociación Internacional de Magistrados de la Juventud y que fue reproducida en $A B C$ (Tele Radio, 1974e: 25). 
de duración) y la ausencia de referencias a los centros de información local sugieren que pudo tratarse de un programa completamente diferente que simplemente compartía nombre con el anteriormente señalado. Sea como fuere, lo cierto es que la etapa de información regional fracasó por las carencias técnicas de los centros regionales ${ }^{17}$.

El segundo título dedicado a la información regional fue Siete días (1969-1972), dirigido por Juan Blanco y al que se dedicaron 44 horas. Se definía simplemente como "Espacio informativo con la actualidad en las distintas provincias españolas". Siete días salió al aire poco después del final de la primera etapa de Crónica 2, pero desapareció de las parrillas casi un año después del comienzo de la segunda, lo que refuerza la hipótesis de la ausencia de información local en la época de Carlos Sentís, pues sería redundante mantener dos programas en antena con la misma temática regional.

Aunque no tuvieron una gran presencia en antena, estos programas representan el esfuerzo más importante de descentralización que emprendió Televisión Española en estos años. No obstante, no se pudo hacer frente a la apuesta de la regionalización por razones técnicas y presupuestarias: la infraestructura informativa del UHF estaba muy poco desarrollada.

\section{Conclusiones}

La información gozó de una importancia destacada en el UHF y se equipara al peso que tenía en otras cadenas europeas. El principal obstáculo para su pleno desarrollo en España no fue curiosamente la acción gubernamental, sino la falta de presupuesto que impidió la consolidación de una infraestructura técnica y humana para hacer frente a los retos que TVE se había marcado: una redacción propia para el Segundo Canal y una información regional amplia y potente. Precisamente estos proyectos hablan de una televisión que, en los años setenta, en el tardofranquismo, tiene una visión amplia y más acorde con los nuevos tiempos de lo que debe ser el papel del medio en la cobertura informativa nacional.

No obstante, y como se ha visto, no puede decirse que la información regional quisiese dar cuenta de las protestas laborales que estaban surgiendo, mayoritariamente, en el tejido industrial de España, ni atender al resurgimiento de la cuestión nacional y territorial de estos años (Núñez Seixa, 2007). La información regional fue breve, por las cuestiones económicas apuntadas, pero se centró sobre todo en temas turísticos y folclóricos. Ello no quiere decir que no contribuyese, en cierta forma, a dar cuenta de la idiosincrasia de cada lugar y alimentar así, indirectamente, las diferentes identidades nacionales.

Los programas dedicados a la actualidad apuntan cuáles fueron los dos principales soportes de la televisión en España: el cine y los deportes. En los Paneles de Aceptación de programas, los cinematográficos se mantienen a la cabeza y Revista de cine

17 "Este intento de descentralización -cada emisión debía tener una bella presentadora de la región- no llegaría a concretarse totalmente, ya que la buena voluntad y el entusiasmo no podían suplir del todo la flagrante carencia de medios de dichas centrales periodísticas" (Baget, 1993: 188). 
y Pantalla grande aprovechan y, al mismo tiempo alientan, ese interés de la audiencia. Lo mismo sucede en la información deportiva. Desde el punto de vista de la programación destaca el sentido continuista de todos estos espacios. No son originales ni en sus contenidos ni en su concepción estética, pero funcionan; al menos la crítica, que no parece encontrar cortapisas en sus comentarios sobre TVE, los valora positivamente. Y eso bastaba para establecer una continuidad y con ella una consolidación del género. A diferencia de los dedicados al cine, los programas deportivos de la Segunda Cadena quisieron distinguirse de la Primera incluyendo información sobre deportes minoritarios, pero el empeño se fue diluyendo con el tiempo. En este caso, la resistencia al cambio procedió de los propios espectadores que no manifestaron mucho interés por estos deportes.

El programa más comprometido con la realidad social fue Cuestión urgente, que abordó temas que la propia industrialización del país y su paulatina modernización social y cultural estaban originando. Ya sólo su planteamiento representó un avance importante en la función social de la televisión en el tardofranquismo, pero su alcance real fue limitado, puesto que el análisis de estas cuestiones se realizó desde una óptica muy concreta que obvió las verdaderas causas y centró su enfoque en el mensaje cristiano.

En definitiva, la información en La 2 se planteó como un complemento de la Primera Cadena: hubo un reparto de funciones y un afán por distinguirse. Pero la falta de presupuesto dificultó los planes iniciales. Sólo fue una realidad la redacción de informativos propia de la Segunda, pero hubo que esperar a finales de 1974. El resto de los pasos que se dieron para buscar la diferenciación informativa con respecto a la Primera fracasaron: o bien por el desinterés de la audiencia, como fue el caso de los deportes minoritarios; o por problemas técnicos y económicos, como sucedió en la información regional.

\section{Referencias}

ALBERTOS, Ana y ORTEGA, María Luisa (2009): "La ciencia en Televisión Española: primeros acercamientos a la divulgación", en GÓMEZ VAQUERO, Laura y SÁNCHEZ SALAS, Daniel: El espíritu del caos. Representación y recepción de las imágenes durante el franquismo. Una recopilación de Secuencias. Revista de Historia del cine. Universidad Autónoma de Madrid. Madrid, págs. 475-502.

BAGET HERMS, Josep Maria (1993): Historia de la televisión en España. Barcelona, Ed. Feed-back.

BONAUT, Joseba (2009): Televisión y deporte. Origen y desarrollo histórico de la programación deportiva española (1956-1975). Buenos Aires, Ed. Libros en Red.

BUSTAMANTE, Enrique (2008): Radio y televisión en España. Historia de una asignatura pendiente de la democracia. Barcelona, Gedisa.

CARRERAS LARIO, Natividad (2009): Estructura y programación de TVE (19581962): los años pioneros. Sevilla, Universidad de Sevilla.

DÍAZ, Lorenzo (2006): 50 años de TVE. Madrid, Alianza Editorial. 
DIEGO, Patricia (2010): La ficción en la pequeña pantalla. Cincuenta años de series en España. Pamplona, Eunsa.

GÓMEZ-ESCALONILLA MORENO, Gloria (2003): Programar televisión. Análisis de los primeros cuarenta años de programación televisiva en España. Madrid, Ed. Dykinson.

HERNÁNDEZ CORCHETE, Sira (2008): La historia contada en televisión. El documental televisivo de divulgación histórica en España. Barcelona, Gedisa.

IBÁÑEZ, Juan Carlos (2009): "La televisión en la España de los años cincuenta. Apuntes sobre el proceso de legitimación del medio televisivo en la dictadura de Franco", en GÓMEZ VAQUERO, Laura y SÁNCHES SALAS, Daniel (Eds.): El espiritu del caos. Representación y recepción de las imágenes durante el franquismo. (Una recopilación de Secuencias. Revista de Historia del cine) Universidad Autónoma de Madrid, Madrid, págs. 283-319.

MARIMÓN, Carlos (1974a): "Bien por Polideportivo", en La Vanguardia, 16-041974, pág. 57.

MARIMÓN, Carlos (1974b): “Cambio de horario”, en La Vanguardia, 13-12-1974, pág. 43.

MARIMÓN, Carlos (1975): “Polideportivo”, en La Vanguardia, 17-01-1975, pág. 29.

NÚÑEZ SEIXAS, Xosé Manuel (2007): “Nuevas y viejos nacionalismos: la cuestión territorial en el tardofranquismo, 1959-1975”, en Ayer, no 68 (4):59-87.

PALACIO, Manuel (2008): Historia de la televisión en España. Barcelona, Gedisa.

PALACIO, Manuel (2012): "Para entender la televisión del franquismo", en GIL GASCÓN, Fátima y MATEOS-PÉREZ, Javier (Eds.): Qué cosas vimos con Franco... Cine, prensa y televisión de 1939 a 1975. Madrid, Rialp.

REVISTA TELE RADIO:

- 1967a: “A todo gas", en Tele-Radio, número 471, 2-8 enero 1967, págs. 26-27.

- 1967b: "El mundo del deporte", en Tele-Radio, número 484, 3-9 abril 1967, págs. 12-15.

-1967c: "La Segunda Cadena", en $A B C, 04-10-1967$, pág. 87.

-1967d: Programación televisiva para la semana del 16 al 22 octubre 1967 en Tele-

Radio, número 512.

-1967e: “Crónica 2”, en ABC, 10-12-1967, pág. 109.

-1969: Programación televisiva para la semana del 27 de enero al 2 de febrero 1969 en Tele-Radio, número 579.

-1970: "Habla el padre Martínez Roura, director del programa. Cuestión urgente", en Tele-Radio, nº 636, 2-8 marzo 1970, pág. 29.

-1971: Programación semanal para el día 19/10/1971 en Tele-Radio, número 721,

18-24 de octubre de 1971. 
-1974a: "A partir de hoy, el fútbol de segunda división en TVE", en ABC Sevilla, 26-02-1974, pág. 61.

-1974b: "Declaraciones del director general de Radio y Televisión. Es casi seguro que antes del verano se generalice la televisión en color", en La Vanguardia, 2303-1974, pág. 33.

-1974c: "Don Marino Peña, director adjunto de TVE”, en $A B C, 04-09-1974$.

-1974d: "Polideportivo: hora y media de programa", en La Vanguardia, 13-091974, pág. 47.

-1974e: "Los tribunales de menores en la Crónica 2", $A B C, 10-10-1974$, pág. 25. -1974f: “TVE: Nuevos espacios informativos para la Segunda Cadena”, en La Vanguardia, 12-11-1974, pág. 69.

-1974g: "Ruiz de Elvira, jefe de los servicios informativos de RNE", en ABC Sevilla, 06-12-1974, pág. 42.

-1975: "En el Segundo Programa Crónica 2 cumplió su tercer aniversario", en Tele-Radio número 899, 17-23 marzo 1975, pág. 22.

-1976a: "Don Francisco Ruiz de Elvira, director de Radio Nacional de España", en La Vanguardia, 29-01-1976, pág. 15.

-1976b: "Nombramientos en Radiotelevisión Española", en La Vanguardia, 2702-1976, pág. 10.

-1986: 30 años de TVE, coleccionable del diario Ya, disponible en http://www.scribd.com/doc/93898436/Historia-de-TVE-Coleccionable-DiarioYa [fecha de consulta: 15 de julio de 2013].

RUEDA LAFFOND, José Carlos, y CHICHARRO MERAYO, María del Mar (2006): La televisión en España (1956-2006). Política, consumo y cultura televisiva. Madrid, Ed. Fragua.

THOVERON, Gabriel (1982): "Chaine publiques-Chaines privees: deux mondes", en La programmation à la radio et à la télévision", Études de radio-télévision, $\mathrm{n}^{\circ} 31$, RTBF, págs. 91 y ss., citado en CONTRERAS, José Miguel y PALACIO, Manuel (2003): La programación de televisión. Madrid, Ed. Síntesis. 